\title{
AUTOLOGOUS TRANS-OBTURATOR (ATO) RECTUS FASCIA SLING IN TREATMENT OF FEMALE STRESS URINARY INCONTINENCE
}

\author{
By
}

\section{Mohamed Fawzy Salman*, Mohamed Mabrook Badr* and Ayman Kotb Korietnah*}

Department of Urology*, Al Azhar Faculty of Medicine, Cairo, Egypt

Mobile: 01111788996, E-mail: prof_mohamed_fawzy@yahoo.com

\begin{abstract}
Background: stress urinary incontinence is a common problem affecting females; treatment varies between Burch colposuspension and traditional tot using synthetic materials.

Objective: To evaluate efficacy and safety of autologous transobturator (ATO) rectus fascia sling as a primary treatment for female stress urinary incontinence.

Materials and Methods: We evaluated the outcomes of 56 consecutive females who underwent ATO sling placement with rectus fascia for stress incontinence from July 2017 to September 2019 at the urology department - Al Azhar university hospitals (Alhussien - Sayed Galal university hospitals). Patients were followed in the outpatient clinic after one week, two weeks, 3 months and 6 months postoperatively. Outcomes were measured subjective by the International Consultation on Incontinence Questionnaire Female Lower Urinary Tract Symptoms (ICIQ-FLUTS) score, and patient reported outcome and objective by cough stress test.
\end{abstract}

ICIQ-FLUTS were compared between pre- and postoperative responses using Wilcoxon signed-rank test. Retreatment-free survival rates were evaluated via Kaplan-Meier method.

Results: The mean age of patients was $43.4 \pm 7.04$ years (29-56 years), 40 patients $(71.5 \%)$ were premenopausal, and 16 patients $(28.5 \%)$ were postmenopausal. The mean BMI was $29.2 \pm 4.1 \mathrm{~kg} / \mathrm{m}^{2}$. The technique was performed and the patient was discharged the next day after surgery. Follow up for patients was carried out at one week, two weeks, three and six months postoperatively. All patients completed ICIQFLUTS at the last follow-up. Compared to preoperative scores, patients who completed ICIQ-FLUTS questionnaires at 6 months $(\mathrm{N}=56)$ showed significant improvement in all domains: frequency, voiding, and incontinence, and in quality of life related to frequency, voiding and incontinence. Among those who completed questionnaires both at 3 months and 6 months after surgery $(\mathrm{N}=56)$. There was no significant deterioration in ICIQ-FLUTS scores. Overall retreatment-free survival rate was $93 \%$ at six months. Notably, none of our patients suffered from severe (Clavien III-V) complications or required sling release.

Conclusion: ATO sling placement appeared safe and effective, with promising short-term outcomes. However, long term follow-up is needed.

Key words: ATO sling, autologous TOT, SUI, Transobturator, Urinary incontinence, Stress incontinence.

\section{INTRODUCTION}

Stress urinary incontinence (SUI) is a common problem, affecting up to $40 \%$ of adult women. That negatively impacts their social, psychologic, and hygienic well-being and quality of life. The pathophysiology of SUI is presumably multifactorial. Many SUI risk factors are related to the pelvic floor musculature or connective tissue weakness. The incidence 
of SUI significantly increases after menopause, particularly in women with coexisting risk factors such as spontaneous and operative vaginal deliveries, multiparty, obesity, and metabolic syndrome (Isali et al; 2020).

Over the last 2 decades, the treatment of stress urinary incontinence (SUI) has shifted to the midurethral sling (MUS) or a mesh-based bladder neck procedure. Although the surgery was believed to be relatively safe, there has been a steep rise in the number of reported cases of their erosion into the lower urinary tract. Mesh erosion was first reported in 2001 but is now recognized as a major long-term complication of MUS surgery with an incidence rate between 0.6 and $5.4 \%$ (Karim, 2020).

The above observations have led to the development of an ATO sling. The main reason for using autologous material is that a synthetic sling has 15 times more chance of erosion than autologous tissue. In addition, autologous tissue presents a lower risk of complications due to inflammatory and foreign body reactions. The ATO sling has been shown to have efficacy and durability without signs of degeneration for more than 4 years after insertion (Laufer et al., 2019).

The present work aimed to evaluate the outcome of ATO rectus fascia sling as a treatment of female SUI.

\section{PATIENTS AND METHODS}

Our study included 56 females complaining of SUI. After approval of the study protocol by the local ethical committee, an informed written consent was obtained from every patient before enrollment into the study after discussion of the treatment options for female SUI. We evaluated the outcomes of 56 consecutive females who underwent ATO sling placement with rectus fascia for stress incontinence from July 2017 to September 2019 at the urology department, Al Azhar university hospitals (Alhussien, Sayed Galal university hospitals).

\section{Inclusion criteria:}

Women with genuine SUI or mixed UI with predominant stress element.

\section{Exclusion criteria:}

Recurrent cases, mixed incontinence with predominant Urge urinary incontinence, associated local abnormalities (e.g. cystocele), and any neurogenic lower urinary tract dysfunction.

Preoperative evaluation included: Full history, 3 days voiding diary and ICIQFLUTS questionnaire, clinical examination and grading of SUI severity by Stamey (1992) classification and BMI. Laboratory investigations included CBC, bleeding profile including prothrombin time and prothrombin concentration, Fasting blood glucose level, liver function tests, serum creatinine and urine analysis and culture and Imaging studies were performed in form of Pelvi abdominal U/S (estimate full bladder capacity and post voiding residual "PVR" urine).Urodynamic assessment in the forms of (Uroflowmetry, Filling cystometry and Pressure flow study) to exclude any neurogenic LUTS disorders or other causes of incontinence.

Following induction of anesthesia and administration of perioperative antibiotic (1g.cefoxitin), the patient was positioned 
in the dorsal lithotomy position, sterilization and draping were done. A sterile Foley catheter 16 French was inserted to drain the bladder, following this, saline was injected for hydrodistention of the anterior vaginal wall, and a midline incision was made based on the mid-urethra (fig.3a). Dissection was carried out bilaterally to the obturator Foramen on both sides.

Through Pfannenstiel incision, $\sim 1 \mathrm{~cm} \times$ $\sim 5 \mathrm{~cm}$ rectus fascia strip was isolated from the anterior rectus sheath (fig.1). Two stay sutures were secured to the corner of the fascial segment on each side (fig.2). Next, two separate trocar passages were performed on each side using a reusable C-shaped trocar, with care taken to ensure at least a $1 \mathrm{~cm}$ tissue bridge in the obturator membrane between the superior and inferior passes. Following this, the stay sutures were tied external to the obturator membrane on both sides (fig.4), leaving the sling secured and flush with the mid-urethra. Sutures were also placed to secure the sling to the periurethral tissue to prevent rolling or migration (fig.3b), (Linder and Elliott, 2016).

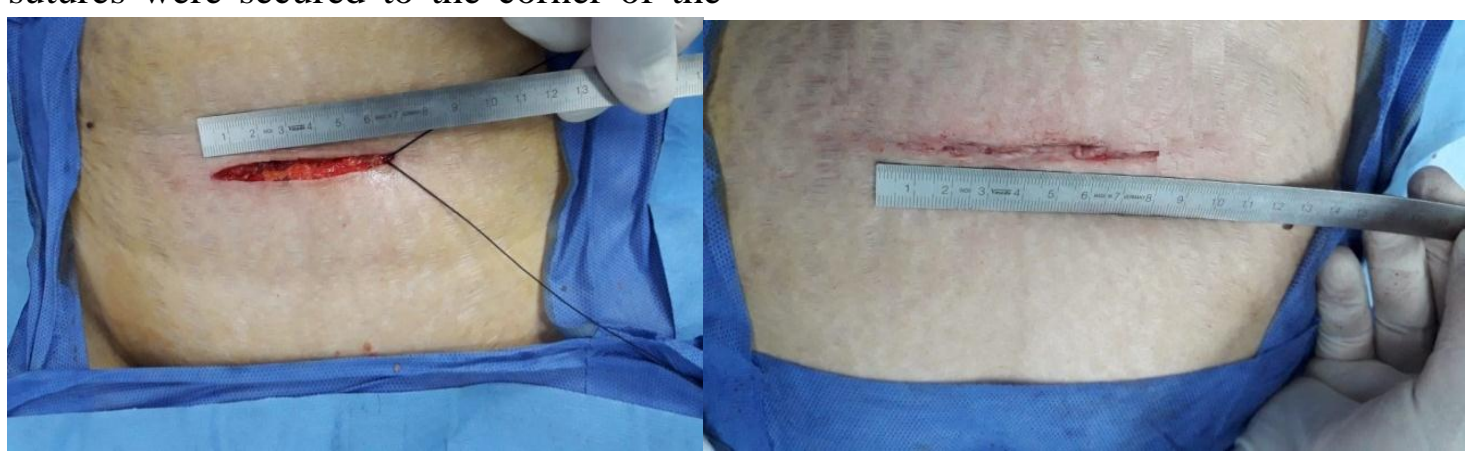

Figure (1 a,b): Through Pfannenstiel incision, $1 \mathrm{~cm} \times 5 \mathrm{~cm}$ rectus fascia strip is isolated from the anterior rectus sheath.

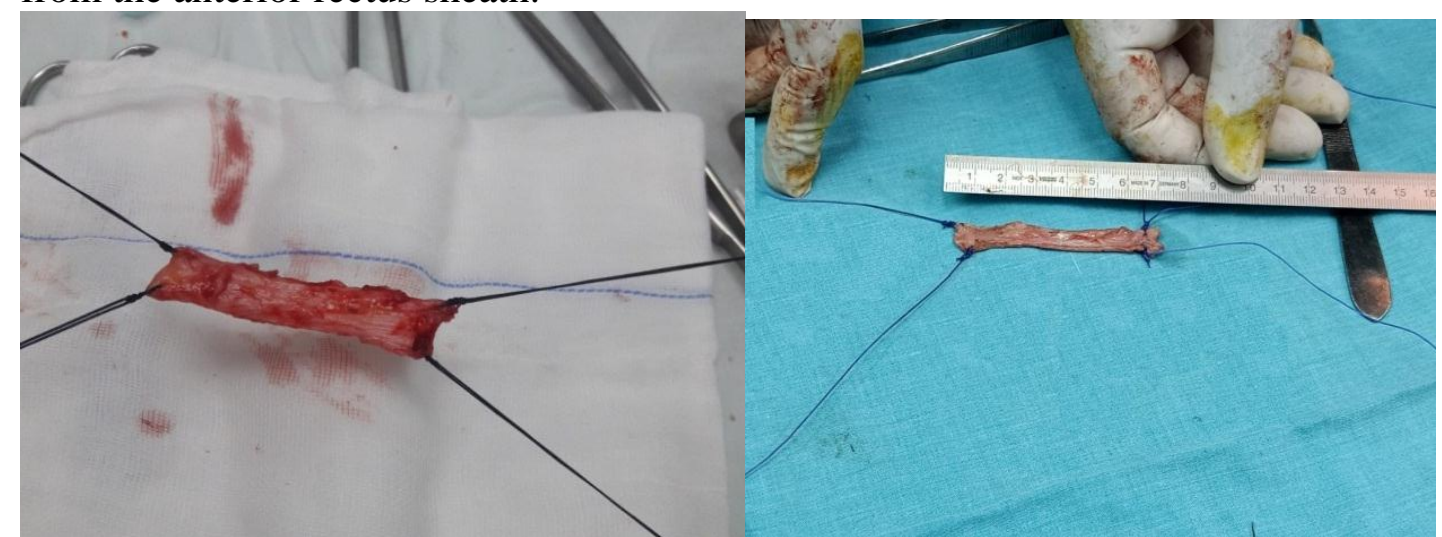

Figure (2 a,b): Two stay sutures are secured to the corner of the fascial segment on each side. 


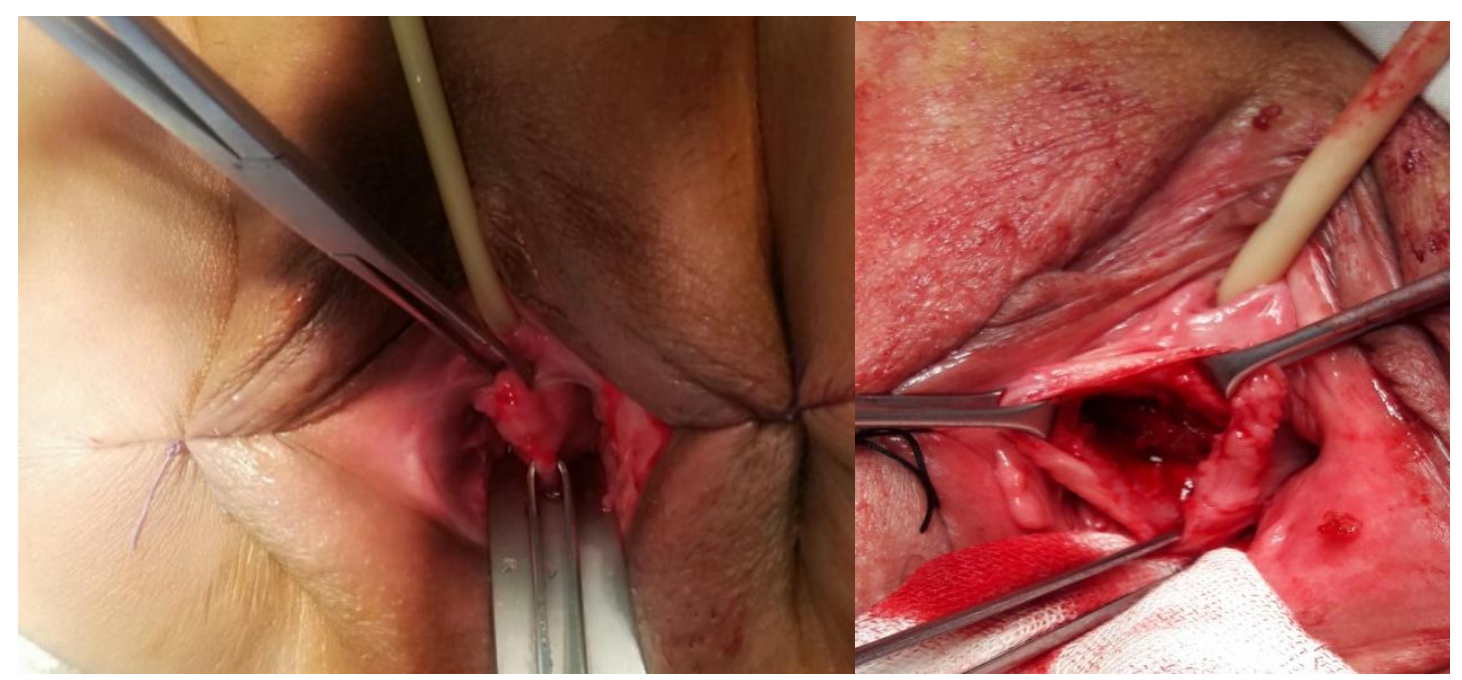

Figure (3 a, b); A: Anterior vaginal wall, and a midline incision is made based on the midurethra. Dissection is carried out bilaterally to the obturator Foramen on both sides. B: Fixation of the fascial tape by two sutures in the periurethral tissue to prevent migration or enrollment of the tape.

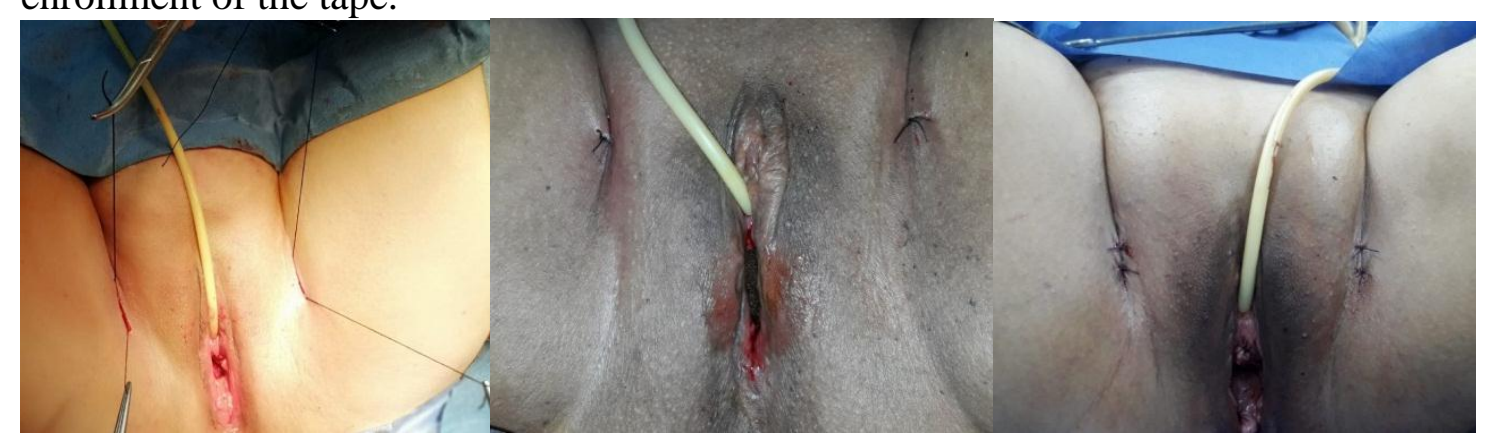

Figure (4 a,b): Ligation of both sutures on both sides then skin closure.

The operative time \& intraoperative incidents were recorded. Blood loss was estimated by counting up the gauzes and towels used during the procedure [fully soaked gauze $=50 \mathrm{ml}$ blood loss; halfsoaked gauze $=30 \mathrm{ml}$ blood loss; fully soaked towel $=150 \mathrm{ml}$ blood loss; halfsoaked towel $=75 \mathrm{ml}$ blood loss] (Shorn, 2009). Intraoperative complications: Pelvic organ injuries including vaginal, bladder, urethra, or major blood vessels were recorded. The patient was kept under observation overnight, then the urethral catheter and vaginal packs were removed and the patient discharged accordingly. The ATO sling procedures were performed and patients were discharged the second day after surgery. Prior to discharge, all patients were assessed for post-void residual urine measured via ultrasound to ensure adequate bladder emptying, defined as greater than $2 / 3$ of bladder capacity (cubuk, 2020). Outcome of surgery was assessed both Objectively by cough stress test and Subjectively: through:
A. Patient reported outcome: Patient was categorized as 'subjectively cured' if no episodes of urine leakage was reported; 'subjectively improved' if the episodes of urine leakage are much less and no more treatment was necessary; and 'subjectively failed' if the patient reported persistence of urine leakage 
and was unsatisfied with the result of surgery.

$\begin{array}{ll}\text { B. Validated } & \text { ICIQ-FLUTS } \\ \text { questionnaire (Linder and Elliott, }\end{array}$ 2016). Perioperative complications were evaluated using the ClavienDindo classification (Clavien et al., 2009).

\section{Statistical analysis:}

Data management and statistical analysis were performed using the Statistical Package for the Social Sciences (SPSS) version 24. Numerical data were summarized using means and standard deviations or medians and ranges. Data were explored for normality using Kolmogrov-Smirnov test and ShapiroWilk test. Categorical data were summarized as percentages. Comparison overtime was done by Friedman test and followed by Wilcoxon signed rank test, multiple comparisons was adjusted by Bonferroni method. All p-values are twosided. $\mathrm{P}$-values $\leq 0.05$ were considered significant.

\section{RESULTS}

Out of 119 female patients represented to our centers (Al-Hussien and Bab AlShereia university hospitals) with genuine stress urinary incontinence, 58 patients of them matched our inclusion criteria and accepted the surgical technique of the study. ATO rectus fascia sling was performed to these 58 patients in the period between July 2017 and September 2019, 2 cases of them lost follow up after the 2nd follow up visit at two weeks, so the total number of patients completed the study follow up were 56 patients.

The mean age of patients was $43.4 \pm$ 7.04 years (29-56 years), 40 patients $(71.4 \%)$ were premenopausal and 16 patients $(28.6 \%)$ were postmenopausal. The mean parity was $4 \pm 1(2-8)$ and none of them had special habits of medical importance (e.g. smoker, drinker, etc.).

Out of the 56 patients, 2 patients (3.6\%) had controlled diabetes type II, 6 patients $(10.7 \%)$ had controlled hypertension, 2 patients $(3.6 \%)$ had bronchial asthma and one patient (1.8\%) on thyroid replacement therapy. In regard to BMI, 7 patients $(12.5 \%)$ were in the normal range $\left(18.5-24.9 \mathrm{~kg} / \mathrm{m}^{2}\right), \quad 25$ patients $(44.6 \%)$ were overweight (25$\left.29.9 \mathrm{~kg} / \mathrm{m}^{2}\right)$ and 24 patients $(42.9 \%)$ were Obese $\left(\geq 30 \mathrm{~kg} / \mathrm{m}^{2}\right)$.

All patients had normal serum creatinine and coagulation profile. The mean pre-operative hemoglobin level was 11.15 gm./dL (median: 10.80; range: 9.50 to 14.00 ; IQR: $1.80 \mathrm{gm} . / \mathrm{dL})$. As evaluated by ultrasonography, the upper urinary tract was normal in all cases (except one case who had non symptomatizing nonfunctioning renal unit) with no concomitant urinary bladder pathology. None of the studied cases had significant post-voiding residual urine. Out of 56 patients matching our inclusion criteria 22 patients $(39.3 \%)$ had pure stress urinary incontinence and 34 patients $(60.7 \%)$ had mixed urinary incontinence with predominant stress element. All patients showed positive cough stress test in preoperative clinical examination. The preoperative clinical Stamey grades of SUI were as follows: 9 patients $(16.1 \%)$ were grade I, 40 patients $(71.4 \%)$ were grade II and 7 patients (12.5\%) were grade III. 
The mean operative time was 53.4 \pm 10.8 minutes (40-80minutes). None of the patients developed brisk hemorrhage or required blood transfusion. No major complication occurred intraoperative; however, urethral injury was identified in 2 cases (3.6\%), surgery was continued in the same manner after 1ry urethral repair and cystoscopic examination of the bladder to exclude any other injuries. Vaginal mucosal tear had happened in 6 cases $(10.7 \%), 2$ at the midurethral incision due to inadvertent Allis clamp traction and 4 occurred by trocar transfixion of the vaginal mucosa laterally. Mucosal trimming and repair was done with no tape exposure later on during follow up visits.

The next morning of surgery vaginal pack and urethral catheter were removed (except the 2 cases who had urethral injury which necessitated catheter fixation for one week) and the patient stayed till voiding multiple times and finally we estimated the post voiding residual urine prior to discharge. All patients were discharged home after 1 day, even the 2 cases that had urethral injury. No cases required more hospital stay or readmission.

During the $1^{\text {st }}$ postoperative visit, the abdominal wound dressing was carried out and in 5 cases $(8.9 \%)$ wound minor complications (seromas) were noted and managed.

Seven cases (12.50\%) were complaining of urgency and 9 patients $(16.1 \%)$ were complaining of voiding difficulties. Pain perception declined with time, at one week follow-up only 14 patients $(25 \%)$ required oral regular analgesics.

One week post-operatively, 49 (87.5\%) patients showed improvement of symptoms; 17 (30.4\%) patients had no symptoms (cured) and $32(57.1 \%)$ patients showed partial improvement of symptoms. However 7 cases were not satisfied at all and cough stress test was still positive and they were considered as preliminary failure (12.5\%). Data are summarized on (Table 1).

Table (1): Follow-up data at one week

\begin{tabular}{|c|c|c|c|}
\hline Data at one week follow-up & & Count & Percent \% \\
\hline \multirow{2}{*}{ UTI } & No Infection & 56 & $100.00 \%$ \\
\hline & UTI & 0 & $0 \%$ \\
\hline \multirow{3}{*}{$\begin{array}{l}\text { De novo Urgency or urge } \\
\text { urinary incontinence. }\end{array}$} & Non & 49 & $87.50 \%$ \\
\hline & Urgency & 7 & $12.50 \%$ \\
\hline & Urge urinary incontinence & 0 & $0 \%$ \\
\hline \multirow{3}{*}{ Voiding difficulties - Retention } & Non & 47 & $84 \%$ \\
\hline & Voiding Difficulties & 9 & $16 \%$ \\
\hline & Urine retention & 0 & $0 \%$ \\
\hline \multirow{4}{*}{ Pain } & No or little Pain & 20 & $25 \%$ \\
\hline & Mild Pain & 22 & $39.28 \%$ \\
\hline & Moderate Pain & 14 & $33.92 \%$ \\
\hline & Severe Pain & 0 & $0 \%$ \\
\hline \multirow{2}{*}{ Abdominal wound healing } & No Complications & 51 & $91.10 \%$ \\
\hline & Minor Complications (Seroma) & 5 & $8.90 \%$ \\
\hline \multirow{2}{*}{ Vaginal wound healing } & No Complications & 54 & $96.42 \%$ \\
\hline & Minor Complications (discharge) & 2 & $3.58 \%$ \\
\hline \multirow{3}{*}{ Post Voiding Residual Urine } & $<100 \mathrm{cc}$ & 36 & $64.30 \%$ \\
\hline & $100-150 \mathrm{cc}$ & 20 & $35.70 \%$ \\
\hline & $>150 \mathrm{cc}$ & 0 & $0 \%$ \\
\hline \multirow{3}{*}{ Outcome after one week } & Cured & 17 & $30.40 \%$ \\
\hline & Improved & 32 & $57.10 \%$ \\
\hline & Failed & 7 & $12.50 \%$ \\
\hline
\end{tabular}


During the $2^{\text {nd }}$ postoperative visit, the abdominal wound dressing was carried out and the subcuticular prolene stitches removed. In 2 cases (3.6\%) mild wound infection was still present and antibiotic was advised according to urine culture.

Four cases $(7.14 \%)$ were complaining of urgency and one case $(1.8 \%)$ had urge urinary incontinence. Urinary tract infection was proved and the initial antibiotic was stopped culture was required. Culture revealed E.choli resistant to ciprofloxacin "previously prescribed" and Amikacin injection was prescribed (Amikin 500 vial/ 12hrs. for 5 days) according to the culture and the symptoms resolved and infection was eradicated. Five cases $(8.9 \%)$ were still complaining of voiding difficulties, however the post voiding residual urine was insignificant (less than 150cc) and patients were improved with serial followup.

Two weeks post-operatively, 49 $(87.5 \%)$ patients showed improvement of symptoms; $27 \quad(48.2 \%)$ patients completely improved (cured) and 22 $(39.3 \%)$ patients partially improved. However 7 cases were not satisfied at all and cough stress test was still positive and they were considered as preliminary failure (12.5\%). Table 2 demonstrates follow up findings at 2 weeks.

Table (1): Follow-up data at the 2nd week

\begin{tabular}{|c|c|c|c|}
\hline Data at 2 weeks follow-up & & Count & $\%$ \\
\hline \multirow{2}{*}{ UTI } & No Infection & 51 & $91.10 \%$ \\
\hline & Infection & 5 & $8.90 \%$ \\
\hline \multirow{3}{*}{$\begin{array}{l}\text { DE novo urgency or urge urinary } \\
\text { incontinence }\end{array}$} & None & 52 & $92.86 \%$ \\
\hline & Urgency & 4 & $7.14 \%$ \\
\hline & Urge Urinary Incontinence & 1 & $1.80 \%$ \\
\hline \multirow{3}{*}{ Voiding difficulties or retention } & None & 51 & $91.10 \%$ \\
\hline & Voiding Difficulties & 5 & $8.90 \%$ \\
\hline & Retention & 0 & $0 \%$ \\
\hline \multirow{4}{*}{ Pain } & No or little Pain & 47 & $84 \%$ \\
\hline & Mild pain & 9 & $16 \%$ \\
\hline & Moderate Pain & 0 & $0 \%$ \\
\hline & Severe Pain & 0 & $0 \%$ \\
\hline \multirow{2}{*}{ Abdominal wound healing } & No Complications & 54 & $96.40 \%$ \\
\hline & Minor Complications & 2 & $3.60 \%$ \\
\hline \multirow{2}{*}{ Vaginal wound healing } & No Complications & 51 & $91.10 \%$ \\
\hline & Little Discharge & 5 & $8.90 \%$ \\
\hline \multirow{3}{*}{ Post Voiding Residual Urine } & $<100 \mathrm{cc}$ & 42 & $75 \%$ \\
\hline & $100 \_150 \mathrm{cc}$ & 14 & $25 \%$ \\
\hline & $>150 \mathrm{cc}$ & 0 & $0 \%$ \\
\hline \multirow{3}{*}{ Outcome at two weeks } & Cured & 27 & $48.20 \%$ \\
\hline & Improved & 22 & $39.30 \%$ \\
\hline & Failed & 7 & $12.50 \%$ \\
\hline
\end{tabular}

During the $3^{\text {rd }}$ postoperative visit at 3 months, examination of the abdominal wound was done and no late wound complications were noticed (incisional hernia, keloid or ugly scar. Also, examination of the vagina was performed and no vaginal extrusion of the fascial tape or significant discharge was noticed. Three patients $(5.3 \%)$ had active UTI (not the same cases who had previous UTI at 2 weeks follow-up), culture and sensitivity tests were requested and antibiotic was prescribed accordingly. These patients 
(5.3\%) were complaining of urgency and one of them $(1.8 \%)$ had urge urinary incontinence.

On the previous follow-up at 2 weeks 5 patients were complaining of voiding difficulties, all of them improved on follow-up at 3 months.

On the 3rd month postoperatively, 52 (92.9\%) patients showed improvement of symptoms; $44 \quad(78.6 \quad \%) \quad$ patients completely improved (cured) and 8 $(14.3 \%)$ patients partially improved. However 4 cases $(7.1 \%)$ were not satisfied at all and cough stress test was still positive and they were considered as preliminary failure. Data are summarized on Table 3.

\section{Table (3): Follow-up data at 3 months}

\begin{tabular}{|c|c|c|c|}
\hline Follow-up data at 3 months & & Count & Percent \% \\
\hline \multirow{2}{*}{ U.T.I. } & No Infection & 53 & $94.70 \%$ \\
\hline & Infection & 3 & $5.3 \%$ \\
\hline \multirow{3}{*}{$\begin{array}{l}\text { DE novo urgency - urge urinary } \\
\text { incontinence }\end{array}$} & Non & 53 & $94.65 \%$ \\
\hline & Urgency & 3 & $5.35 \%$ \\
\hline & Urge Urinary Incontinence & 1 & $1.80 \%$ \\
\hline \multirow{3}{*}{ Voiding difficulties or retention } & Non & 56 & $100.00 \%$ \\
\hline & Voiding difficulties & 0 & $0 \%$ \\
\hline & Retention & 0 & $0 \%$ \\
\hline \multirow{4}{*}{ Pain } & No or little Pain & 56 & $100 \%$ \\
\hline & Mild Pain & 0 & $0 \%$ \\
\hline & Moderate pain & 0 & $0 \%$ \\
\hline & Severe pain & 0 & $0 \%$ \\
\hline \multirow{2}{*}{ Abdominal wound healing } & No Complications & 56 & $100 \%$ \\
\hline & Minor Complications & 0 & $0 \%$ \\
\hline \multirow{2}{*}{ Vaginal wound healing } & No Complications & 51 & $91.10 \%$ \\
\hline & Little Discharge & 5 & $8.90 \%$ \\
\hline \multirow{3}{*}{ Post Voiding Residual Urine } & $<100 \mathrm{cc}$ & 56 & $100 \%$ \\
\hline & $100-150 \mathrm{cc}$ & 0 & $0 \%$ \\
\hline & $>150 \mathrm{cc}$ & 0 & $0 \%$ \\
\hline \multirow{3}{*}{ Outcome at 3 months } & Cured & 44 & $78.60 \%$ \\
\hline & Improved & 8 & $14.30 \%$ \\
\hline & Failed & 4 & $7.10 \%$ \\
\hline
\end{tabular}

During the $4^{\text {th }}$ postoperative visit at six months, examination of the abdominal wound was done and no wound complications were noticed. Also no vaginal extrusion of the fascial tape was detected.

Four cases (7.1\%) were complaining of urgency and one of these cases $(1.8 \%)$ had urge urinary incontinence. All of the previous 4 cases had UTI and once infection was eradicated the symptoms improved.

Six patients $(10.7 \%)$ had active UTI (not the same cases of previous UTI at 2 weeks or 3 months follow-up), culture and sensitivity tests were requested and antibiotic was prescribed accordingly.

None of the patients was complaining of voiding difficulties at 6 months.

Cough stress test was negative in 52 patients $(92.9 \%)$ and positive in 4patients (7.1\%).

On the $6^{\text {th }}$ month postoperative, 52 (92.9\%) patients showed improvement of symptoms; $44 \quad(78.6 \%)$ completely improved (cured) and $8(14.3 \%)$ showed partial improvement. However 4 cases (7.1\%) were not satisfied at all and cough stress test was still positive and they were considered as treatment failure Table 4 . It 
was noticed that the outcome at the $6^{\text {th }}$

Data are demonstrated in Table 4. month was the same as that at 3 months.

Table (2): Data at six months follow-up

\begin{tabular}{|c|c|c|c|}
\hline Follow-up data at 6 months & & Count & Percent \% \\
\hline \multirow[t]{2}{*}{ 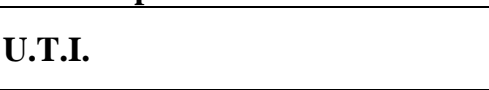 } & No Infection & 50 & $89.30 \%$ \\
\hline & Infection & 6 & $10.70 \%$ \\
\hline \multirow{3}{*}{$\begin{array}{l}\text { DE novo urgency - urge urinary } \\
\text { incontinence }\end{array}$} & Non & 52 & $92.85 \%$ \\
\hline & Urgency & 4 & $7.15 \%$ \\
\hline & Urge Urinary Incontinence & 1 & $1.8 \%$ \\
\hline \multirow{3}{*}{ Voiding difficulties or retention } & Non & 56 & $100.00 \%$ \\
\hline & Voiding difficulties & 0 & $0 \%$ \\
\hline & Retention & 0 & $0 \%$ \\
\hline \multirow{4}{*}{ Pain } & No or little Pain & 56 & $100 \%$ \\
\hline & Mild Pain & 0 & $0 \%$ \\
\hline & Moderate pain & 0 & $0 \%$ \\
\hline & Severe pain & 0 & $0 \%$ \\
\hline \multirow{2}{*}{ Abdominal wound healing } & No Complications & 56 & $100 \%$ \\
\hline & Minor Complications & 0 & $0 \%$ \\
\hline \multirow{2}{*}{ Vaginal wound healing } & No Complications & 51 & $91.10 \%$ \\
\hline & Little Discharge & 5 & $8.90 \%$ \\
\hline \multirow{2}{*}{ Cough stress test } & Negative & 52 & $92.90 \%$ \\
\hline & Positive & 4 & $7.10 \%$ \\
\hline \multirow{3}{*}{ Post Voiding Residual Urine } & $<100 \mathrm{cc}$ & 56 & $100 \%$ \\
\hline & $100-150 \mathrm{cc}$ & 0 & $0 \%$ \\
\hline & $>150 \mathrm{cc}$ & 0 & $0 \%$ \\
\hline \multirow{3}{*}{ Outcome at 6 months } & Cured & 44 & $78.60 \%$ \\
\hline & Improved & 8 & $14.30 \%$ \\
\hline & Failed & 4 & $7.10 \%$ \\
\hline
\end{tabular}

Clavien-Dindo grading system for the classification of surgical complications:

Intraoperatively, 2 patients had urethral injury and required prolonged catheter fixation and were considered as grade II Clavien-Dindo complication. In the early postoperative period (1st week after surgery) one patient had severe unusual pain which necessitated additional analgesic and was considered as grade I Clavien-Dindo complication. At one week follow-up, five patients $(8.9 \%)$ developed minor wound complications (seroma), which required bedside management and were considered as grade I Clavien-Dindo complication. No high grade (grade III or grade IV or grade V) complications occurred intraoperatively or during follow-up.

The preoperative ICIQ- FLUTS questionnaire and during various follow-up intervals were collectively listed in Table (5). 
Table (5): Preoperative and post-operative ICIQ- FLUTS questionnaire

\begin{tabular}{|c|c|c|c|c|c|c|}
\hline Time of Evaluation & Pre-operative & $\mathbf{1}$ Week & $\mathbf{2}$ Weeks & $\mathbf{3}$ Months & $\mathbf{6}$ Months & \\
\hline ICIQ & Median (range) & $\begin{array}{c}\text { Median } \\
\text { (range) }\end{array}$ & $\begin{array}{c}\text { Median } \\
\text { (range) }\end{array}$ & $\begin{array}{c}\text { Median } \\
\text { (range) }\end{array}$ & $\begin{array}{c}\text { Median } \\
\text { (range) }\end{array}$ & p value \\
\hline Filling & $5(3-8)^{\mathrm{a}}$ & $2(0-4)$ & $2(0-6)$ & $1(0-6)$ & $1(0-6)$ & $<0.001$ \\
\hline Filling QOL & $15(9-25)^{\mathrm{a}}$ & $4(0-12)$ & $4(0-18)$ & $2.5(0-18)$ & $2.5(0-18)$ & $<0.001$ \\
\hline Voiding & $0(0-1)$ & $1(0-9)^{\mathrm{b}}$ & $1(0-9)$ & $1(0-2)$ & $1(0-2)$ & $<0.001$ \\
\hline Voiding QOL & $0(0-2)$ & $2(0-20)^{\mathrm{b}}$ & $2(0-18)$ & $2(0-4)$ & $2(0-4)$ & $<0.001$ \\
\hline incontinence & $14(12-15)^{\mathrm{a}}$ & $2(0-15)$ & $1(0-13)$ & $1(0-11)$ & $1(0-11)$ & $<0.001$ \\
\hline incontinence QOL & $40(33-45)^{\mathrm{a}}$ & $4(0-40)$ & $2(0-35)$ & $2(0-30)$ & $2(0-28)$ & $<0.001$ \\
\hline
\end{tabular}
a: pre wer statistically significant from other times, b: 1 week wer statistically significant from all other times

Changes in ICIQ- FLUTS Filling and QOL questionnaire with serial followup:

Filling symptoms in the ICIQ- FLUTS questionnaire (Nocturia, Urgency, Bladder pain and Frequency) showed significant improvement post-surgery and subsequently the QOL showed significant improvement as compared to preoperative score (Fig.5a and Fig.5b).
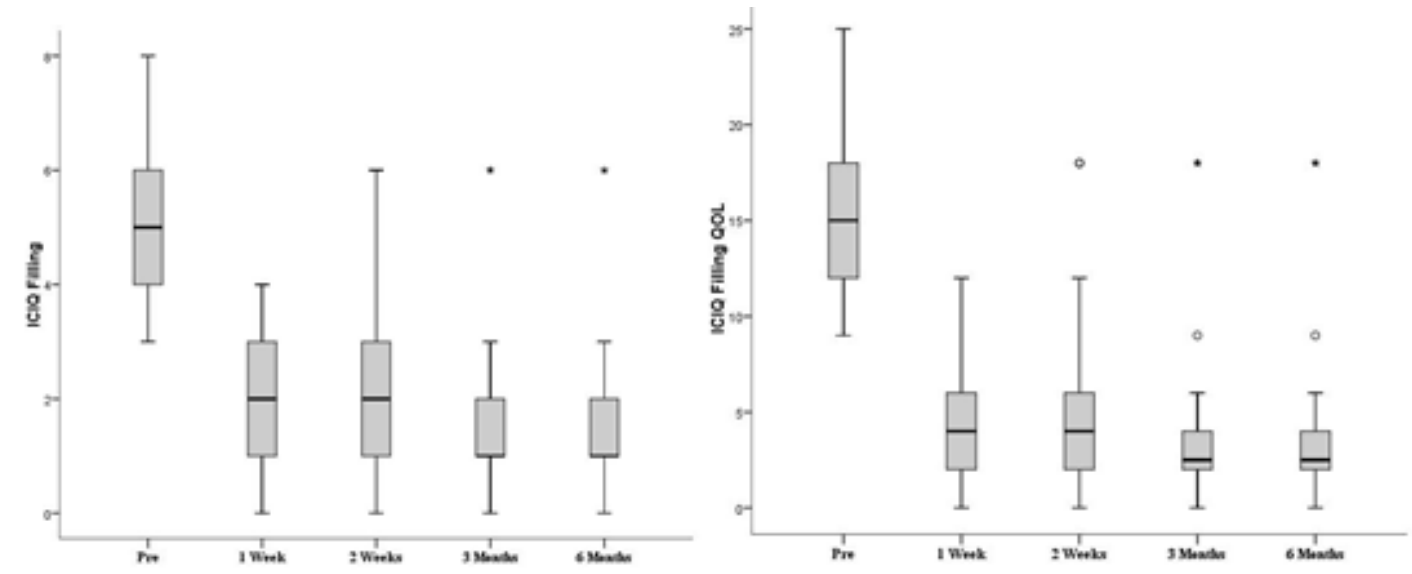

Figure (5a,b): ICIQ-FLUTS filling and filling-QOL changes pre and postoperative. A: preoperative is statically significant from all times

Changes in ICIQ- FLUTS Voiding and QOL questionnaire with serial followup:

Voiding symptoms in the ICIQFLUTS questionnaire (hesitancy, straining and intermittency) increased significantly in the early post-operative period but recurred near the normal values with time after surgery. Twenty patients $(35.7 \%)$ developed voiding difficulties early after surgery (at hospital discharge) but at one week follow up, only 9 patients $(16.1 \%)$ had voiding difficulties.

At 2 weeks follow-up only 5 patients $(8.9 \%)$ had voiding difficulties, all improved at 3 and 6 months follow-up. (Figures 6 a, b) show changes in ICIQFLUTS voiding and QOL questionnaire with serial follow-up as compared to preoperative score. 

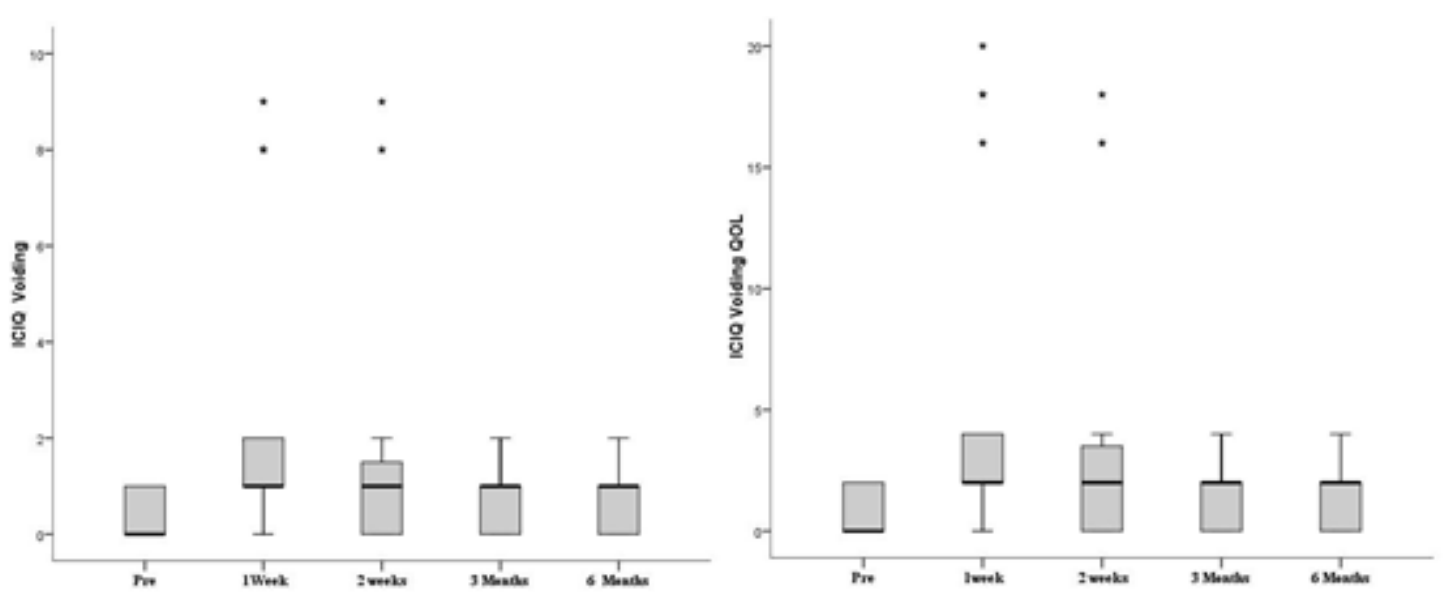

Figure (6a,b): ICIQ-FLUTS voiding and voiding - QOL changes pre and postoperative

A: preoperative is statically significant from all times

Changes in ICIQ- FLUTS Incontinence and QOL questionnaire with serial follow-up:

Incontinence symptoms in the ICIQFLUTS questionnaire (urge urinary incontinence, frequency of urinary incontinence, stress urinary incontinence, unexplained urinary incontinence and nocturnal enuresis) showed significant improvement post-surgery and subsequently the QOL showed significant improvement as compared to preoperative score (fig.7a and fig.7b).
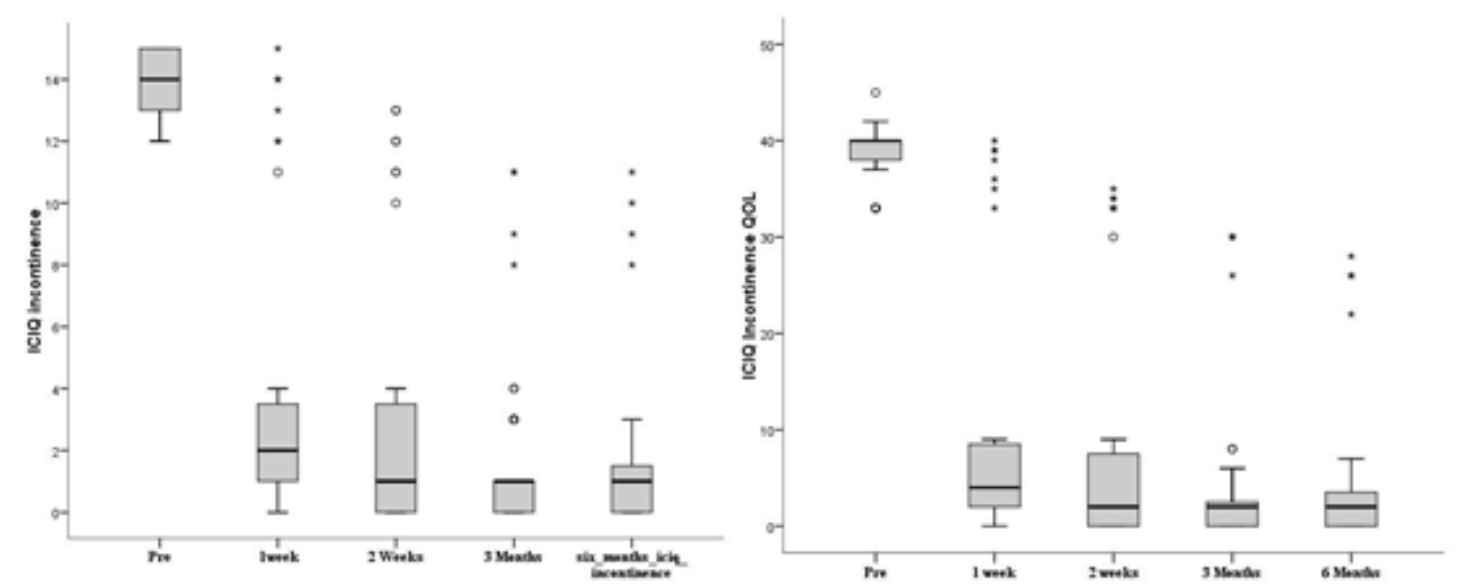

(Figure 7a,b): ICIQ-FLUTS incontinence and incontinence- QOL changes pre and postoperative

A: preoperative is statically significant from all times

\section{DISCUSSION}

Prior to the development of synthetic mid-urethral slings, the autologous pubovaginal sling was the mainstay of surgical SUI therapy. Notably, the autologous pubovaginal sling has been demonstrated to have long-term efficacy (Linder and Elliotts, 2016).

Regarding initial data, the mean age of patients was $43.4 \pm 7.04$ years. The mean 
BMI was $29.2 \pm 4.1 \mathrm{~kg} / \mathrm{m}^{2}$. It's comparable with Cubuk et al.(2020) (age $51.7 \pm 9.8$ years - BMI $28.8 \pm 3.9$ ) and Laufer et al. (2019) stated that age was 51 years and the median BMI 28 $\mathrm{kg} / \mathrm{m}^{2}$.Linder and Elliott (2016), stated that The median age was 62 years old and median BMI $28.6 \mathrm{~kg} / \mathrm{m}^{2}$.

As the obesity is a major risk factor of SUI. Our study can't change this rule. The mean BMI was $29.2 \pm 4.1 \mathrm{~kg} / \mathrm{m}^{2}$ (21.736). Only 7 patients $(12.5 \%)$ were in the normal range $\left(18.5-24.9 \mathrm{~kg} / \mathrm{m}^{2}\right), \quad 25$ patients $(44.6 \%)$ were overweight (25$29.9 \mathrm{~kg} / \mathrm{m}^{2}$ ) and $24(42.9 \%)$ were Obese $\left(\geq 30 \mathrm{~kg} / \mathrm{m}^{2}\right)$. Also all studied patients were multipara and no nulliparous cases were included. 40 patients $(71.5 \%)$ were premenopausal and 16 patients $(28.5 \%)$ were postmenopausal.

Regarding the operative time, in our study the mean operative time was 53.4 minutes. It was comparable to the operative time reported by Linder and Elliott (2016) which was 56.5 minutes, and in 2014 by the same group was 60 minutes, Cubuk and his colleagues (2020) reported operative time of 43.8 minutes, Laufer and his colleagues (2019) reported 75 minutes operative time.

It's reported in the literature that Pubovaginal slings (PVS), Burch colposuspention (BC) and mid urethral slings (MUS) with a non-absorbable synthetic material have similar complication rates (Fusco et al., 2017; Mahdy \& Ghoniem.2018; Blaivas et al., 2019 and Palos et al., 2019). For instance, perioperative bleeding requiring blood transfusion is a serious problem associated with all of these procedures and may occur in up to $2 \%$ of the cases (Sohlberg and Elliott, 2019).

In the present study, however, no patient had significant blood loss. Another feared complication of these three techniques is bowel, bladder or urethral injury which has been reported in up to 9\% of the cases (Fusco et al., 2017; Mahdy and Ghoniem.2018; Palos et al., 2019 and Blaivas et al., 2019). Higher rates were reported after retropubic procedures for bladder, vascular and bowel injuries (Fusco et al., 2017). In contrast, TOT provides technical advantages in terms of avoiding perioperative organ injury and has been reported to cause bladder or urethra injury in only a limited number of cases (Ford et al., 2015). In our study, no intraoperative visceral injury was observed in any patient.

Erosion of mesh into the vagina, bladder, or urethra is a complication of MUS using synthetic materials, which has been reported in $0.7-2 \%$ of the cases (Gomes et al., 2017). No differences were reported among the TOT and RT procedures (Fusco et al., 2017). The etiological factors of this complication include inadequate vaginal closure, wound infection, early sexual intercourse and excessive tension of the sling. In contrast, PVS do not cause mesh erosions due to its autologous structure (Fusco et al., 2017 and Ghoniem \& Rizk, 2018). In our study, no erosion was observed, the same as Cubuk et al. (2020) however had one patient who had a minimal vaginal exposure of fascial graft that was smaller than $1 \mathrm{~cm}$, which was successfully treated with topical estradiol. Based on these findings, they considered that the usage of 
autologous graft with proper tension is of critical importance for obtaining favorable outcomes.

Although some authers recommend pubovaginal slings in treatment of severe SUI in which ISD is suspected or present due to high failure rate of traditional TOT (Fusco et al., 2017). Our study included 7 cases of severe SUI and ISD was present in all of them, only one of this group required retreatment, and six patients were free of symptoms postoperatively (85\% success rate for this group of patients). Cubuk et al. (2020) studied 17 patients with severe SUI (17/22) who underwent the same procedure, all cases improved post-operatively, with only one case of treatment faliure.

Regarding the overall success rate in our study the success rate of was $93 \%$ (52/56). In the study done by Cubuk and his Colleagues (2020), the subjective cure rate was $100 \%$ (22/22). Linder and Elliott in 2016 reported $85 \%(28 / 33)$ success rate and only 5 patients required retreatment after one year. Laufer and his Colleagues (2019) reported an overall success rate of $94.5 \%$ (17/18). These results are comparable to our results.

\section{CONCLUSION}

ATO approach using an autologous sling was found to be technically feasible, safe and efficacious for the treatment of SUI among properly selected candidates. However, longer follow- up period and larger cohorts are needed to validate this procedure.

\section{REFERENCES}

1. Blaivas JG, Simma-Chiang V, Gul Z, Dayan L, Kalkan S and Daniel M. (2019): Surgery for Stress Urinary Incontinence:
Autologous Fascial Sling. Urol Clin North Am; 46(1):41-52.

2. Clavien PA, Barkun J, de Oliveira ML, Vauthey JN, Dindo D, Schulick RD, de Santibañes E, Pekolj J, Slankamenac K, Bassi C, Graf R, Vonlanthen R, Padbury R, Cameron JL, Makuuchi M. (2009): The Clavien-Dindo classification of surgical complications: five-year experience. Ann Surg.; 250(2):187-96.

3. Cubuk A, Yanaral F, Savun M, Ayranci A, Erbin A, Yazici O, Akbulut MF, Sarilar O. (2020): Modified autologous transobturator tape surgery - evaluation of short term results. Ginekol Pol; 91(2):51-56.

4. Ford AA, Rogerson L, Cody JD, Aluko P, Ogah JA. (2015): Mid-urethral sling operations for stress urinary incontinence in women. Cochrane Database Syst Rev. 31; 7(7).

5. Fusco F, Abdel-Fattah M, Chapple CR, Creta M, La Falce S, Waltregny $D$ and Novara G. (2017): Updated Systematic Review and Meta-analysis of the Comparative Data on Colposuspensions, Pubovaginal Slings, and Midurethral Tapes in the Surgical Treatment of Female Stress Urinary Incontinence. Eur Urol; 72(4): 567591.

6. Ghoniem GM and Rizk DEE (2018): Renaissance of the autologous pubovaginal sling. Int Urogynecol J.; 29(2):177-178.

7. Gomes CM, Carvalho FL, Bellucci CHS, Hemerly TS, Baracat F, de Bessa J Jr, Srougi $M$ and Bruschini H. (2017): Update on complications of synthetic suburethral slings. Int Braz J Urol.;43(5):822-834.

8. Isali I, Mahran A, Khalifa AO, Sheyn D, Neudecker M, Qureshi A, Conroy B, Schumacher FR, Hijaz AK, El-Nashar SA. (2020): Gene expression in stress urinary incontinence: a systematic review. International Urogynecology Journal 31, pages1-14.

9. Karim S. (2020): Role of Endoscopic Management in Synthetic Sling/Mesh Erosion Following Previous Incontinence Surgery: A Systematic Review From 
European Association of Urologists Young Academic Urologists (YAU) and Urotechnology (ESUT) Groups. Int Urogynecol J, 31 (1), 45-53.

10. Laufer J, Scasso S, Bentancor V, Bertoche C, Sosa CG and Elliott DS. (2019): Autologous transobturator sling as an alternative therapy for stress urinary incontinence. Int $\mathrm{J}$ Gynaecol Obstet.; 145(3):300-305.

11. Linder BJ and Elliott DS (2015): Autologous transobturator urethral sling placement for female stress urinary incontinence. J Urol.; 193(3):991-6.

12. Linder BJ and Elliott DS (2016): Autologous transobturator urethral sling placement for female stress urinary incontinence: Short-term outcomes. Urology.; 93:55-59.

13. Mahdy A and Ghoniem G. (2018): Autologous rectus fascia sling for treatment of stress urinary incontinence in women: A review of the literature. Neuro-urol Urodyn.; 38(S4): 51-58.

14. Palos CC, Maturana AP, Ghersel FR, Fernandes CE and Oliveira E. (2019): Randomized controlled trial comparing minisling with transobturator sling for the treatment of stress urinary incontinence. Neurourol Urodyn.; 37(7):2184-2190.

15. Shorn MN (2009): Measurement of blood loss: review of literature. J Midwif Wom Health; 55(1): 20-27.

16. Sohlberg EM, Elliott CS (2019): Burch Colposuspension. Urol Clin North Am.; 46(1): 53-59.

17. Stamey TA. (1992): Urinary incontinence in the female: The Stamey endoscopic suspension. In: Campbell's urology. Walsh ,P.C.(Eds), W.B. Saunders Company, 6th edition, P.2829 


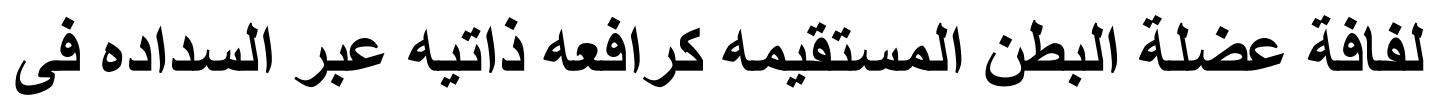

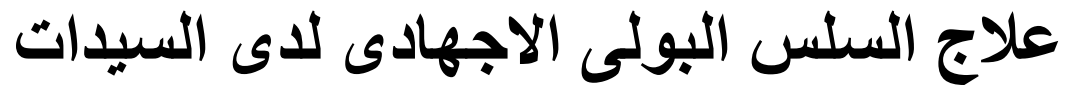

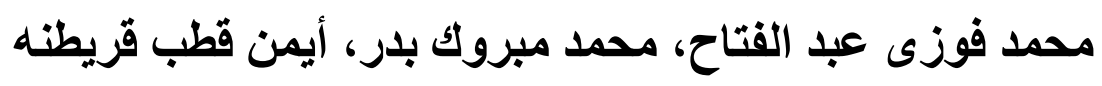 قسم جراحة المسالك البولية، كلية الطب، جامعة الأزهر، القاهرة، مصر فئر}

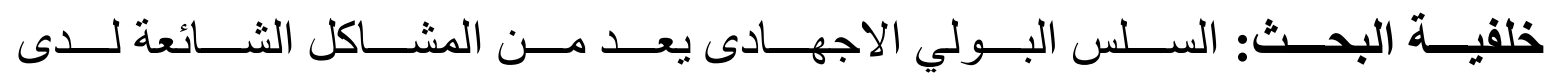

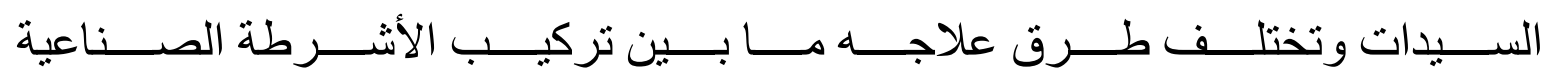
و واستخدام منظار البطن ولكل من هده التقنيات مشاكله الخاصة به.

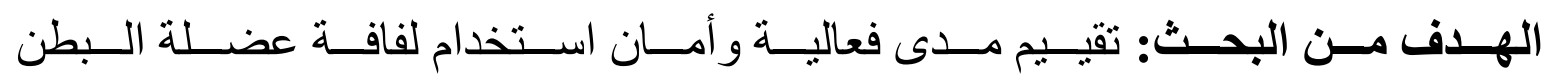
المستقيمة كعلاج لحالات السلس البولى الاجهادى لدي السيدات.

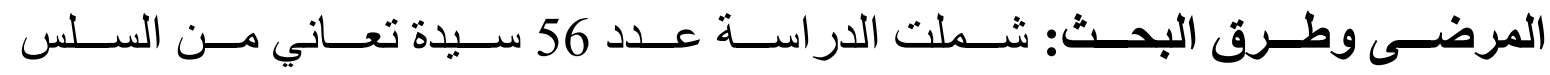

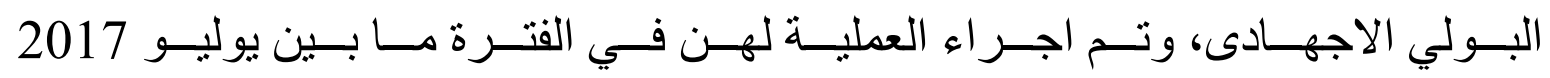

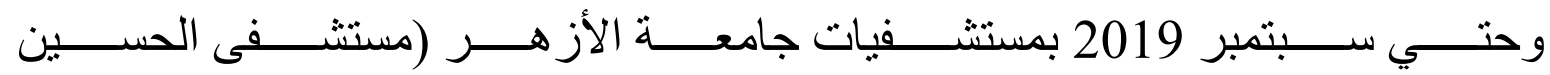

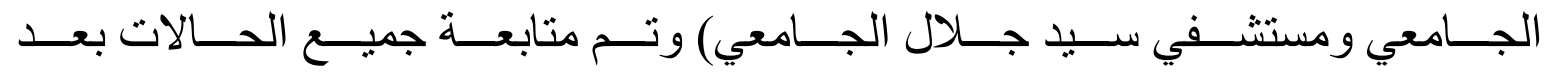

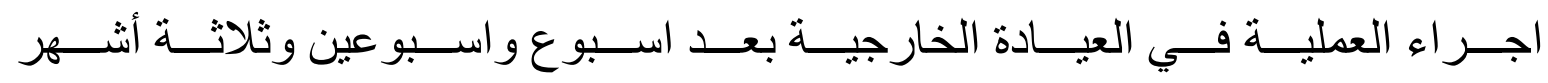

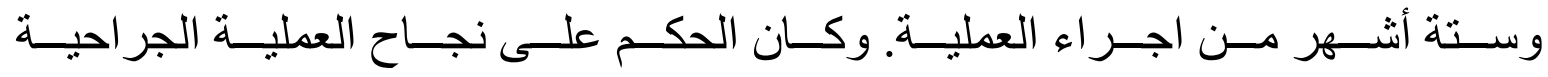

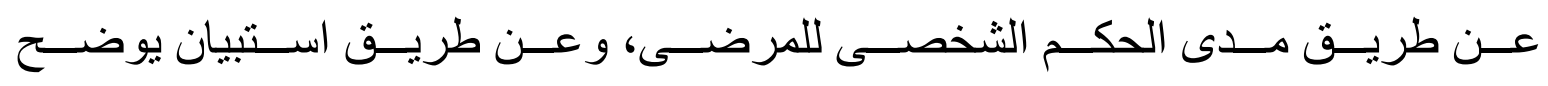
أعر اض المرض ومدى تحسنها.وتمت مقارنة النتائج قبل وبعد العطلية.

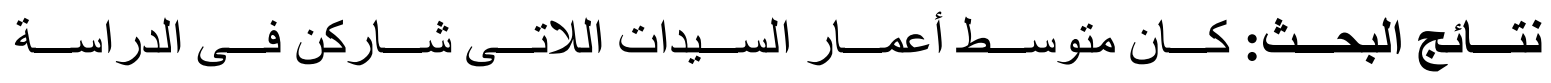

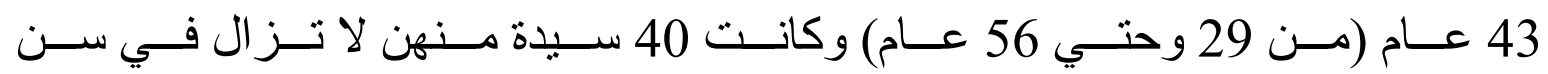

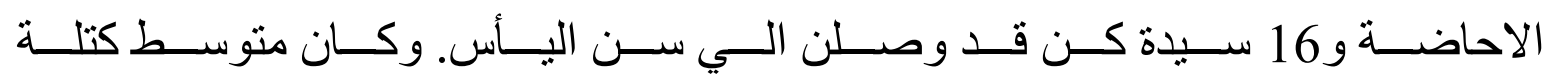

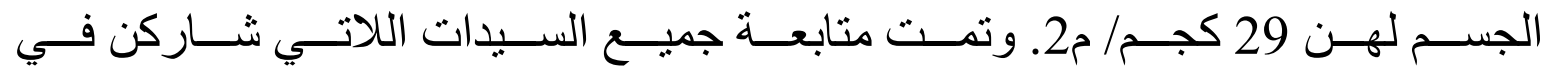

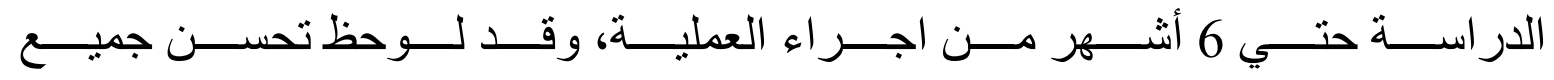




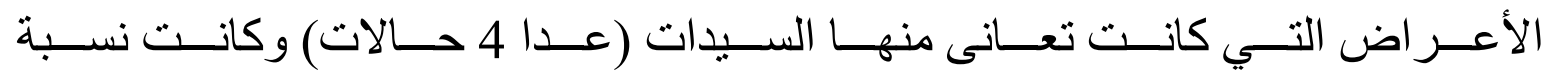
نجاح العملية 93\%. ولم تحدث أية مضاعفات خطيرة نتيجة العملية.

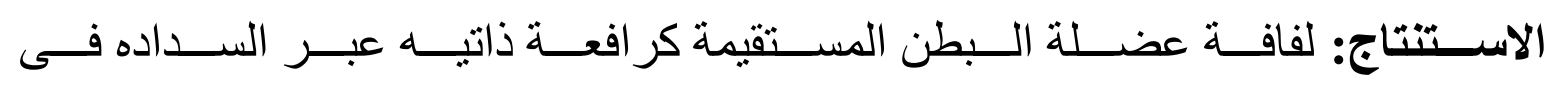

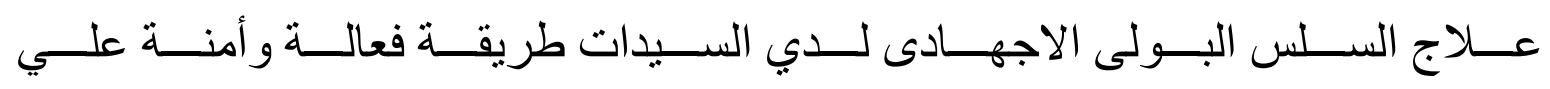

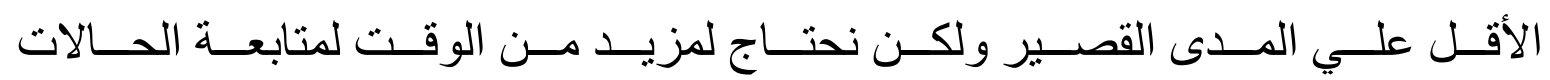
لفتر ات أطول للحكم علي فعالية هذه الطريقة علي المدى البعيد. 